\title{
The human microbiome and genitourinary malignancies
}

\author{
Michael Nicolaro, Daniella E. Portal, Brian Shinder, Hiren V. Patel, Eric A. Singer \\ Section of Urologic Oncology, Rutgers Cancer Institute of New Jersey and Robert Wood Johnson Medical School, New Brunswick, New Jersey, \\ USA \\ Contributions: (I) Conception and design: M Nicolaro, EA Singer, DE Portal,; (II) Administrative support: EA Singer; (III) Provision of study \\ materials or patients: EA Singer; (IV) Collection and assembly of data: All authors; (V) Data analysis and interpretation: M Nicolaro, DE Portal, HV \\ Patel, B Shinder,; (VI) Manuscript writing: All authors; (VII) Final approval of manuscript: All authors. \\ Correspondence to: Eric A. Singer, MD, MA, MS, FACS. Rutgers Cancer Institute of New Jersey, 195 Little Albany Street, Room 4563, New \\ Brunswick, NJ 08903, USA. Email: eric.singer@rutgers.edu.
}

\begin{abstract}
The human microbiome contains a vast network of understudied organisms that have an intimate role in our health and wellness. These microbiomes differ greatly between individuals, creating what may be thought of as a unique and dynamic microbial signature. Microbes have been shown to have various roles in metabolism, local and systemic inflammation, as well as immunity. Recent findings have confirmed the importance of both the gut and urinary microbiomes in genitourinary malignancies. Numerous studies have identified differences in microbial signatures between healthy patients and those with urologic malignancies. The microbiomes have been shown to contain microbes that may contribute to the etiology of disease state as well as yield information in regard to a person's health and their responsiveness to certain drugs such as immune checkpoint inhibitors (ICIs) and tyrosine kinase inhibitors (TKIs). Less well understood are the effects of antibiotics on oncologic outcomes in such treatment courses. This review will explore our current understanding and advancements in the field of microbiome research and discuss its intimate association with genitourinary diseases including bladder cancer, prostate cancer, and kidney cancer. With a better understanding of the association between the microbiome and genitourinary malignancy, further investigation may produce reliable predictors of disease, prognostic indicators as well as therapeutic targets.
\end{abstract}

Keywords: Genitourinary; microbiome; genitourinary malignancy

Submitted Mar 29, 2020. Accepted for publication Aug 28, 2020.

doi: 10.21037/atm-20-2976

View this article at: http://dx.doi.org/10.21037/atm-20-2976

\section{Introduction}

The close interactions between humans and bacteria have been studied for quite some time. Although bacteria are often thought of as pathogenic to their human hosts, we now know that they exist within nearly every organ system of the body in both commensal and mutualistic relationships $(1,2)$. Not surprisingly, these organisms can have profound effects on both normal physiology and disease states (1).

The total assembly of microorganisms within a given community is collectively referred to as a microbiome. In many ways, the idea that microbiota is associated with our health is actually quite familiar to the general population. An estimated one in five Americans take probiotics, which seek to supplement the "normal" bacterial flora in our digestive systems to improve digestive health (3). In 2008, the National Institute of Health (NIH) sought to characterize our microbiome in order to better understand its role in human health and disease by establishing the Human Microbiome Project (HMP), which generated the largest microbial genome databases for different body sites including nares, oral cavity, skin, GI tract, breast, and urogenital (GU) tract (4). Recently, it was shown that the urinary microbiome in women may be influenced by age, menopausal status, and sexual activity (5). With advances in high-throughput sequencing, transcriptomics, and metabolomics this endeavor has led to multiple reports intimately linking the human microbiome to various 
pathological processes such as aging, atherosclerosis, obesity, diabetes, CNS dysfunction, and even malignancies such as colorectal cancers (6-8). New evidence has also revealed that the composition of a person's microbiome may be a useful tool as a predictive biomarker for malignant processes, but can also be a target to be manipulated for therapeutic benefits (9).

The role of the microbiome in the development and treatment of GU malignancies is just starting to be appreciated. This review explores our current understanding of the human microbiota in relation to $\mathrm{GU}$ malignancies and discusses advancements in its manipulation for disease benefit.

\section{The microbiome}

Our body's microbiome has been linked to a variety of health conditions, likely through its effect on metabolism, tissue development, inflammation, and immunity $(10,11)$. It has been demonstrated that microbial flora of the gut and intestinal tract can promote various malignancies such as colorectal, liver, and pancreatic cancers (12). Additionally, key work in the murine model has shown the powerful role of gut microbiota in influencing the response of tumors to both chemo- and immunotherapeutic agents via a modulation of the tumor microenvironment $(10,13)$. Thus, manipulation of the microbiome is a potential mechanism by which the course of disease can be altered. Initially, the HMP predominantly focused on characterizing the gut flora, but later was expanded to include the GU tract, mouth, vagina, skin, and nasal cavity (14). The bladder was notably left out of these early endeavors as urine was widely considered to be sterile. However, this dogma was challenged when more sophisticated detection techniques were employed to examine urine specimens. Various investigators were able to use 16s rRNA sequencing to identify urinary organisms in both men and women who had negative urine cultures based on standard laboratory testing (15-17). Furthermore, Hilt et al. used an expanded quantitative urine culture protocol to show that many of these species identified were in fact culturable (18). As detection of these different bacteria has challenged the dogma of "sterile" urine, it has also brought to light the role the genitourinary microbiome may play in GU health.

\section{The microbiome and bladder cancer}

One of the earliest links between GU microbiome and malignancy was with our understanding of Schistosoma haematobium infections. S. haematobium is a species of parasitic blood flukes that can infect the urinary tract causing schistosomiasis and has been associated with the development of squamous cell carcinoma (SCC) of the bladder $(19,20)$. Prior to the availability of effective treatments for schistosomiasis, endemic areas such as in the Middle East and Africa had a much higher incidence of bladder cancer than the rest of the world. In the 1970s, nearly one in three solid malignancies in Egypt was bladder cancer (21). As with other causes of bladder SCC, it appears that inflammatory changes precipitated by S. haematobium organisms are the culprit. In a leading hypothesis, it is proposed that the inflammatory responses occur following the implantation of the parasite's eggs into the bladder wall. Byproducts of these reactions may include nitrosamine formation and other carcinogenic free radicals, which mediate malignant transformation (22-24). Interestingly, there is evidence that the urinary microbiome could mediate some of these reactions. Adebayo et al. found that distinct GU microbiota existed within the urine samples from patients who were healthy, those who had schistosomal infections but no resultant pathology, and those with schistosomal induced bladder pathology (25). Some of organisms differentially found in patients with schistosomal induced bladder pathology, including Fusobacterium, Sphingobacterium, Bacteroides, and Enterococcus, are known mediators of inflammatory and immunogenic processes, suggesting their presence may influence schistosomiasis disease progression. Nevertheless, further research is needed to understand the exact mechanism by which the microbiota within the bladder promote malignant transformation following schistosomal infections.

Comparative analysis of the GU microbiome between patients with and without bladder cancer has also provided important insight into how distinct bacterial species may be related to disease progression and recurrence (Table 1).

Wu et al. collected and compared urine samples from 31 patients with urothelial carcinoma of the bladder and 18 healthy controls. Interestingly, there was a larger bacterial diversity in the bladder cancer cohort and various bacterial species were differentially observed in this cohort (28). Similar results were seen in an analysis by Bučević Popović et al. in which the genus Fusobacterium was overrepresented in the bladder cancer cohort (27). Although no clear microbial signature has been developed that can serve as a "microbial biomarker" of malignancy, comparing the urinary microbiome in patients with and without various 
Table 1 Selection of studies evaluating compositional differences of bacteria in urine samples of patients with urothelial carcinoma

\begin{tabular}{|c|c|c|c|c|c|}
\hline Study & Patient population & \multicolumn{2}{|c|}{ Higher abundance in bladder cancer } & \multicolumn{2}{|c|}{ Higher abundance in healthy control } \\
\hline Xu et al. (26) & $\begin{array}{l}\text { Patients with } \\
\text { urothelial carcinoma }\end{array}$ & $\begin{array}{l}\text { Streptococcus, } \\
\text { Pseudomonas, } \\
\text { Anaerococcus }\end{array}$ & Not evaluated & Not evaluated & Not evaluated \\
\hline $\begin{array}{l}\text { Bucević } \\
\text { Popović et al. } \\
(27)\end{array}$ & $\begin{array}{l}\text { Male patients with } \\
\text { non-muscle } \\
\text { invasive UC of the } \\
\text { bladder }\end{array}$ & $\begin{array}{l}\text { Fusobacterium, } \\
\text { Actinobaculum, } \\
\text { Facklamia, } \\
\text { Campylobacter }\end{array}$ & $\begin{array}{l}\text { Species: Campylobacter } \\
\text { hominis, Actinobaculum } \\
\text { massiliense, Jonquetella } \\
\text { anthropi }\end{array}$ & $\begin{array}{c}\text { Veillonella, } \\
\text { Streptococcus, } \\
\text { Corynebacterium }\end{array}$ & $\begin{array}{l}\text { Veillonella dispar, } \\
\text { Sreptococcus cristatus, } \\
\text { Corynebacterium } \\
\text { appendicis }\end{array}$ \\
\hline Wu et al. (28) & $\begin{array}{l}\text { Male patients with } \\
\text { UC of the bladder }\end{array}$ & $\begin{array}{c}\text { Acinetobacter, } \\
\text { Anaerococcus, } \\
\text { Rubrobacter, } \\
\text { Sphingobacterium, } \\
\text { Atopostipes, } \\
\text { Geobacillus }\end{array}$ & Not evaluated & $\begin{array}{c}\text { Serratia, Proteus, } \\
\text { Roseomonas, } \\
\text { Ruminiclostridium-6, and } \\
\text { Eubacterium-xylanoph }\end{array}$ & Not evaluated \\
\hline
\end{tabular}

UC, urothelial carcinoma.

GU malignancies is shaping our understanding of how the microbiome may be involved in the disease process.

While the GU microbiome has a possible role in bladder cancer progression, it may also play a role in treatment resistance. Intravesical administration of Bacillus CalmetteGuerin (BCG), a live-attenuated strain of Mycobacterium bovis, after transurethral resection of bladder tumor (TURBT) is the standard first-line therapy for high grade non-muscle invasive bladder cancer (NMIBC) (29). However, approximately $20-40 \%$ of patients are unresponsive to BCG therapy and up to $20 \%$ progress to muscle invasive disease $(30,31)$. Although there is no agreement on how resistance to BCG develops, some investigators have postulated that the GU microbiome may place a role in modulating the response to BCG therapy by competitively binding cellular components, such as fibronectin and $\alpha_{5} \beta_{1}$ integrins, required for BCG activity (32). McMillan et al. showed that Lactobacillus iners, which is found in the GU microbiome, binds fibronectin with higher affinity than any other species (33). Characterization of the GU microbiome for patients with NMIBC treated with BCG highlighted that Proteobacteria were enriched in patients with recurrent disease whereas there was an enrichment of Lactobacillales in patients without recurrence. This may suggest that Lactobacillus synergizes with BCG to amplify the elicited response to treatment; however, further work needs to be done to determine the exact mechanism by which the GU microbiome affects BCG therapy.

Additionally, the role of the microbiome in modulating systemic immunotherapeutic agents will need to be evaluated given the recent approval of the PD-1/PD-L1 inhibitors for advanced urothelial carcinoma (UC) of the bladder, including those who are BCG-unresponsive (34-38). Later in this review we discuss the work of Routy and colleagues who examined the effect of antibiotics on treatment outcomes for a small cohort of patients with advanced UC treated with PD-1 inhibitors (Table 2) (39). To date, most studies looking at the interaction between the microbiome and immunotherapy have focused on the gut microbiome. Future work should explore the role of the urinary microbiome in greater detail.

\section{The microbiome and prostate cancer}

Emerging data from several recent studies has provided interesting insight about the microbiome related to prostate cancer $(\mathrm{PCa})$. It has been proposed that proinflammatory bacteria in the urinary microbiome may contribute to carcinogenesis (43). Comparative analysis of urine samples taken from men with biopsy proven prostate cancer and men with negative biopsies did not demonstrate any clear clustering of bacterial species but did identify a cluster of pro-inflammatory bacteria that was enriched within the PCa cohort (44) (Table 3).

Recent work from Banerjee $e t$ al. used next-generation sequencing to compare the microbiome within prostate tissue samples from PCa to benign prostate hyperplasia and found three different microbial signatures that could 
Table 2 Studies evaluating the effect of antibiotics on immunotherapeutic agents in GU malignancies

\begin{tabular}{|c|c|c|c|}
\hline Study & Patient population (n) & Systemic treatment & Outcome \\
\hline $\begin{array}{l}\text { Hahn et al. } \\
(40)\end{array}$ & Metastatic RCC & VEGF-TKI & $\begin{array}{l}\text { PFS: } 18.0 \text { months (abx with Bacteroides coverage) vs. } 8 \text { months } \\
\text { (without abx); HR 0.52, 95\% Cl: } 0.24-1.00 ; \mathrm{P}=0.052\end{array}$ \\
\hline $\begin{array}{l}\text { Derosa et al. } \\
(41)\end{array}$ & Advanced RCC $(n=121)$ & PD-1/PD-L1, CTLA-4 & $\begin{array}{l}\text { PFS: } 7.4 \text { months (no abx) vs. } 1.9 \text { months (abx), HR } 3.1 \text { (1.4-6.9), } \mathrm{P}<0.01 \\
\text { OS: } 30.6 \text { months (no abx) vs. } 17.3 \text { months (abx); HR 3.5, (1.1-10.8), } \mathrm{P}=0.03\end{array}$ \\
\hline $\begin{array}{l}\text { Lalani et al. } \\
(42)\end{array}$ & $\begin{array}{l}\text { Metastatic RCC: } \\
\text { institutional cohort } \\
(n=146) \text {; trial-database } \\
(n=4,144)\end{array}$ & $\begin{array}{l}\text { PD-1/PD-L1, } \\
\text { interferon-alpha, mTOR } \\
\text { inhibitor, VEGF-TKI }\end{array}$ & $\begin{array}{l}\text { PFS-8.1 months (no abx) vs. } 2.6 \text { months (abx), HR } 1.96(1.20-3.20) \text {, } \\
\text { P=0.007; OS: } 79 \text { months (no abx) vs. } 65 \text { months (abx), HR } 1.44 \text { (0.75-2.77), } \\
P=0.27 \\
\text { PFS: } 7.0 \text { months (no abx) vs. } 5.2 \text { months (abx), HR } 1.17 \text { (1.04-1.30), } \\
P=0.008 \text {; OS: } 19.5 \text { months (no abx) vs. } 14.5 \text { months (abx), HR } 1.25 \\
\text { (1.10-1.41), P<0.001 }\end{array}$ \\
\hline
\end{tabular}

GU, genitourinary; HR, hazard ratio; mTOR, mechanistic target of rapamycin; OS, overall survival; PD-1/PD-L1, programmed cell death-1/ programmed cell death ligand-1; PFS, progression-free survival; RCC, renal cell carcinoma; UC, urothelial carcinoma; VEGF-TKI, vascular endothelial growth factor tyrosine kinase inhibitor.

Table 3 Selection of studies evaluating compositional differences of bacteria in urine samples of patients with prostate carcinoma

\begin{tabular}{|c|c|c|c|}
\hline Study & Type of sample & Higher abundance in prostate cancer & Higher abundance in healthy controls \\
\hline Liss et al. (45) & $\begin{array}{l}\text { Rectal swabs from men } \\
\text { undergoing prostate biopsy }\end{array}$ & Bacteroides, Streptococcus & Not reported \\
\hline $\begin{array}{l}\text { Sfanos et al. } \\
(47)\end{array}$ & $\begin{array}{l}\text { Rectal swabs from men with } \\
\text { different clinical states of } \\
\text { prostate cancer }\end{array}$ & $\begin{array}{l}\text { Higher in men taking androgen axis target } \\
\text { therapy: Akkermansia muciniphila, } \\
\text { Ruminococcaceae spp., Lachnospiraceae spp. } \\
\text { Lower in men on ADT: (family) Brevibacteriaceae, } \\
\text { Erysipelorichaceae, Streptococcaceae }\end{array}$ & Not reported \\
\hline \multirow[t]{2}{*}{$\begin{array}{l}\text { Alanee et al. } \\
\text { (49) }\end{array}$} & $\begin{array}{l}\text { Voided urine after prostatic } \\
\text { massage }\end{array}$ & $\begin{array}{l}\text { Increased: Veillonella, Streptococcus, } \\
\text { Bacteroides; Lower: faecalibacterium, lactobaccili, } \\
\text { Actinetobacter }\end{array}$ & Not reported \\
\hline & Rectal swab & Increased Bacteroides & Not reported \\
\hline
\end{tabular}

ADT, androgen deprivation therapy; spp, species. 
be correlated to the stage, grade, and Gleason score of the PCa. Furthermore, they found that the microbiome was not limited to bacterial species, but had a diversity of viruses, fungi, and parasites that were differentially identified (50). This is in contrast to Feng and colleagues who failed to find any significant differences in the abundance of bacterial taxa in prostate tissue samples between a cohort of patients with and without prostate cancer (48). Clearly a significant amount of heterogeneity in the microbiome exists among patients, making validation of any microbial signatures difficult.

Composition of the intestinal microbiome has also been linked to prostate cancer. Liss et al. performed rectal swabs on men prior to prostate biopsies and then correlated the microbiome to the cancer status (45). Among patients with prostate cancer, Bacteroides and Streptococcal species were enriched, as well as pathways linked to folate and arginine metabolism. Similarly, comparison of GI microbiome from men with prostate cancer to $\mathrm{BPH}$ in a separate analysis demonstrated enrichment of Bacteroides in prostate cancer and Faecalibacterium and Eubacterium in BPH (46). Interestingly, Bacteroides has been shown to be increased in both urine samples and stool samples among men with prostate cancer compared to healthy controls in other studies as well, highlighting its potential role as an underlying factor in prostate cancer development (49) (Table 3).

In a similar study, Sfanos and colleagues collected rectal swabs from 21 patients with prostate cancer and found significant compositional diversity compared to healthy controls (47). Furthermore, they showed that Ruminococcaceae and Akkermansia muciniphila were significantly more prevalent in men taking oral androgen receptor axis-targeted therapies. The authors did not investigate a cause-effect relationship, or whether they had consequences for treatment response and patient survival. However, they did hypothesize that their findings represent a possible explanation for why PD-1 inhibition elicited a response in patients with metastatic prostate cancer who progressed on enzalutamide therapy as prior reports have shown that the same types of bacteria were associated with a positive response to anti-PD-1 immunotherapy (39,51-53).

Radiotherapy is one of the mainstay therapies to treat prostate cancer. However, radiation-induced side effects such as radiation enteropathy can limit the amount of radiation dosing. Reis Ferreira et al. examined three cohorts of patients with acute enteropathy, late enteropathy, and a cohort who underwent colonoscopies in the Microbiotaand Radiotherapy-Induced Gastrointestinal Side-Effects
(MARS) study (54). Interestingly, decreased bacterial diversity was observed in patients who experienced radiation enteropathy, with increased counts of Clostridium $I V$, Roseburia, and Phascolarctobacterium in these patients as well. The role of an altered microbiota on developing radiation enteropathy due to the pelvic radiation has significant implications for possible therapies for assessing and treating these side-effects.

\section{The microbiome and kidney cancer}

Epidemiologic evidence has also supported a role of the urinary microbiome in GU malignancies. For example, a population-based analysis of the Iowa Cancer Registry found that a history of a urinary tract infection (UTI) conferred a higher risk of having renal cell carcinoma (RCC) (OR 1.9; 95\% CI: 1.5-2.5) after controlling for known modifiable risk factors such as BMI, smoking, hypertension, and alcohol consumption (55). Nevertheless, in this study men that were smokers with history of UTI had the highest risks of RCC suggesting that other modifiable factors can also be critical for developing RCC.

Recent data also suggests that the GI microbiome may play an important role in the development side effects from the systemic therapies for metastatic RCC. Systemic targeted therapy and immunotherapy are important tools in the treatment of GU malignancies. For RCC, tyrosine kinase inhibitors (TKI) that target the vascular endothelial growth factor receptor (VEGF) are first-line treatment options for patients with stage IV disease (56). Unfortunately, these treatments are sometimes associated with harsh toxicity profiles including cardiotoxicity, hypertension, thrombosis, thyroid dysfunction, skin toxicity, and diarrhea (57). One of the most common side effects, diarrhea, has been reported in up to $51 \%$ of patients undergoing VEGF TKI therapy, with $10 \%$ of patients having grade 3-4 diarrhea (58-60). Those affected by this may be required to have dose reductions, which can alter treatment efficacy, or the discontinuation of the drug altogether. To date, the exact etiology of this side effect is not known and no definitive methods for preventing or managing it exists. Some have suggested that these drugs directly damage the colonic mucosa, with the gut microbiome potentially mediating this interaction (61).

Recently, Pal et al., prospectively enrolled 20 patients with metastatic RCC who would receive VEGF-TKI therapy (61). These patients had no prior history of bowel disease, of which 12 patients did report symptomatic 
diarrhea during treatment while 8 were without this symptom. The patients gave a single stool sample during their treatment and 16s rRNA sequences from the stool were gathered to quantify the relative abundance of microbiota in each group. They found that higher levels of Bacteroides and lower levels of Prevotella were in patients with diarrhea, with the opposite present in those without diarrhea. These findings are consistent with preclinical studies in mice revealing that an increase in Bacteroides spp. is associated with an increase in chemotherapy-induced diarrhea $(62,63)$. Hahn and colleagues attempted to evaluate these findings in a clinical context by analyzing the effect of antibiotic therapy on patients who underwent VEGF-TKI treatment for metastatic RCC (40). They retrospectively analyzed 145 patients who during their treatment either received (I) no antibiotics, (II) antibiotics with Bacteroides spp. coverage, or (III) antibiotics without Bacteroides spp. coverage. Based on the aforementioned studies, it was hypothesized that targeting Bacteroides with antibiotics would result in less diarrhea and improved tolerance of VEGF-TKIs. While no difference in dose reductions were seen between the groups, there was an improved progression-free survival (PFS) for patients who took antibiotics directed against Bacteroides. It is likely that any effect antibiotics may have on oncologic outcomes is more complex than just their influence on the severity of diarrhea and should be further investigated. Regardless, these studies provided preliminary evidence that microbiome alterations can modulate the effect of therapeutic agents.

Our current understanding of the immunogenic nature of genitourinary malignancies and the development of therapies that target the immune response has shifted the paradigm in the treatment of advanced disease states. Immune checkpoint blockade via the PD-1/PD-L1 and CTLA-4 pathways has demonstrated durable responses, with various FDA approved agents now available for both urothelial and kidney cancers (34,38,64-68). Nevertheless, resistance is seen in a subset of patients and the microbiome has been implicated in mediating this response $(10,69)$ (Table 2). Routy et al. looked at patients who were enrolled in clinical trials evaluating nivolumab [NIVOREN (70) and Checkmate 025 (67)] and atezolizumab [PCD4989g (71)] for advanced RCC and durvalumab for patients with advanced urothelial carcinoma of the bladder (UC) [MEDI47361108 (37)] (39). This cohort consisted of 67 patients with RCC and 42 with bladder UC. Oncologic outcomes of these patients were compared for those who were prescribed antibiotics for any reason within two months before or after starting immune checkpoint blockade therapy. Interestingly, antibiotic therapy significantly decreased PFS in both the RCC (7.4 vs. 4.3 months, $\mathrm{P}=0.012)$ and $\mathrm{UC}(4.3$ vs. 1.8 months, $\mathrm{P}=0.049)$ cohorts. OS was significantly shortened in antibiotic treated groups as well when all patients of study were considered (20.6 vs. 11.5 months, $\mathrm{P}<0.001$ ). These findings support the claim that antibiotic effects on oncologic outcomes are complex and must be further investigated. The authors also performed metagenomic profiling of 40 patients with RCC who underwent PD-1 therapy to quantify the composition of the microbiome. They found an overrepresentation of various bacterial species such as Akkermansia muciniphila in patients with longer PFS suggesting an enrichment of this species might help mediate the treatment effect.

An analysis from a single institution's database showed similar results (41). This study examined 121 patients with advanced RCC treated, 16 of whom took antibiotics within 60 days of starting immune checkpoint inhibitor (ICI) treatment. Antibiotic therapy was associated with a significantly increased risk of progressive disease and shorter PFS and OS. In a larger analysis, Lalani and colleagues analyzed 146 patients from an institutional cohort with metastatic RCC who received PD-1/PD-L1, as well as 4,144 patients from a clinical trial participant database (42). The cohort included 709 patients that received antibiotics immediately prior to or after initiating an ICI. Those who had antibiotics had a significant lower objective response rate (ORR 19.3\% vs. 24.2\%, $\mathrm{P}=0.005$ ), shorter PFS (adjusted HR 1.15, 95\% CI: 1.04-1.30, $\mathrm{P}=0.008$ ), and worse OS (adjusted HR $1.25,95 \% \mathrm{CI}$ : $1.10-1.41, \mathrm{P}<0.001)$. Similar findings were found in the institutional cohort, where 31 patients had antibiotic treatment, which was associated with a significantly lower objective response rate, PFS, and a trend towards a lower OS. Taken together, these studies suggest antibiotic therapy may be associated with worse outcomes in patients receiving immunotherapy. This appears to contrast with the work showing improved survival when Bacteroides spp. is targeted with antibiotics in patients undergoing VEGFTKI treatment. The mechanisms driving these findings are not known, though differences in how the systemic agents interact with the microbiome may play a role. Additionally, available studies are retrospective in nature and thus subject to inherent biases. Findings should therefore encourage future prospective evaluations.

Collectively, the results of these clinical studies suggest 
a biologic relationship between gut microbiome and immunotherapy efficacy, though the exact mechanism is unknown. It is possible that there are innate immunogenic bacteria required for the activation of these drugs, and antibiotic therapy results in their elimination (41). Fecal microbiota transplantation has been looked at as a way to reconstitute the responsiveness to immune checkpoint inhibition in mice. In one such study, stool samples from human subjects with RCC who did or did not respond to PD-1 blockade were collected and transplanted into mice (39). These mice were then orthotopically injected with an RCC cell line resistant to PD-1 therapy and then given a CTLA-4 and PD-1 blocker. Imaging analyses determined stool transplantation from patients who had responded to PD-1 therapy conferred a higher antitumor activity than mice receiving stool from non-responders (39), further suggesting an intimate role between the GI microbiota and ICI efficacy.

\section{Conclusions}

Recent evidence strongly suggests that the human microbiome plays various roles in the pathogenesis and management of GU malignancies. Though these interactions are complex and not completely defined, preclinical and clinical data show that microbial organisms are intricately related to these disease processes. With further work both the gut, and the recently described urinary microbiome, may soon be used as reliable predictors of disease occurrence and prognostic indicators. Although there are numerous published studies on the urinary microbiome's role in bladder, kidney and prostate cancer, there is a lack of published research on the urinary microbiome's role in other GU malignancies such as penile cancer and testicular cancer. This warrants investigation in future studies. Additionally, the manipulation of the microbiome by means such as antibiotic or probiotic use might one day be employed for therapeutic purposes. Welldesigned prospective trials will aid in incubating these ideas and bringing them closer to routine clinical use. Nascent efforts to understand the role of the microbiome and GU malignancy have predominantly examined the role of bacterial abundance in disease processes. The role of viral, fungal, bacterial interplay in promoting disease progression and treatment response remains to be understood and may be an important avenue for identifying patients at high risk for progression or treatment failure.

\section{Acknowledgments}

Funding: This work is supported by a grant from the National Cancer Institute (P30CA072720).

\section{Footnote}

Peer Review File: Available at http://dx.doi.org/10.21037/ atm-20-2976

Conflicts of Interest: All authors have completed the ICMJE uniform disclosure form (available at http://dx.doi. org/10.21037/atm-20-2976). EAS receives research support from Astellas/Medivation. EAS is an of the Editorial Board Member. The authors have no other conflicts of interest to declare.

Ethical Statement: The authors are accountable for all aspects of the work in ensuring that questions related to the accuracy or integrity of any part of the work are appropriately investigated and resolved.

Open Access Statement: This is an Open Access article distributed in accordance with the Creative Commons Attribution-NonCommercial-NoDerivs 4.0 International License (CC BY-NC-ND 4.0), which permits the noncommercial replication and distribution of the article with the strict proviso that no changes or edits are made and the original work is properly cited (including links to both the formal publication through the relevant DOI and the license). See: https://creativecommons.org/licenses/by-nc-nd/4.0/.

\section{References}

1. Sender R, Fuchs S, Milo R. Revised Estimates for the Number of Human and Bacteria Cells in the Body. PLoS Biol 2016;14:e1002533.

2. Quigley EM. Gut bacteria in health and disease. Gastroenterol Hepatol (N Y) 2013;9:560-9.

3. Wilkins T, Sequoia J. Probiotics for Gastrointestinal Conditions: A Summary of the Evidence. Am Fam Physician 2017;96:170-8.

4. Turnbaugh PJ, Ley RE, Hamady M, et al. The human microbiome project. Nature 2007;449:804-10.

5. Chen YB, Hochstedler B, Pham TT, et al. The Urethral Microbiota - A Missing Link in the Female Urinary Microbiota. J Urol 2020. doi: 101097ju0000000000000910. 
6. Devaraj S, Hemarajata P, Versalovic J. The human gut microbiome and body metabolism: implications for obesity and diabetes. Clin Chem 2013;59:617-28.

7. Cryan JF, Dinan TG. Mind-altering microorganisms: the impact of the gut microbiota on brain and behaviour. Nat Rev Neurosci 2012;13:701-12.

8. Purcell RV, Visnovska M, Biggs PJ, et al. Distinct gut microbiome patterns associate with consensus molecular subtypes of colorectal cancer. Sci Rep 2017;7:11590.

9. Yi M, Qin S, Chu Q, et al. The role of gut microbiota in immune checkpoint inhibitor therapy. Hepatobiliary Surg Nutr 2018;7:481-3.

10. Iida N, Dzutsev A, Stewart CA, et al. Commensal bacteria control cancer response to therapy by modulating the tumor microenvironment. Science 2013;342:967-70.

11. Lee YK, Mazmanian SK. Has the microbiota played a critical role in the evolution of the adaptive immune system? Science 2010;330:1768-73.

12. Schwabe RF, Jobin C. The microbiome and cancer. Nat Rev Cancer 2013;13:800-12.

13. Viaud S, Saccheri F, Mignot G, et al. The intestinal microbiota modulates the anticancer immune effects of cyclophosphamide. Science 2013;342:971-6.

14. NIH HMP Working Group; Peterson J, Garges S, et al. The NIH Human Microbiome Project. Genome Res 2009; 19:2317-23.

15. Nelson DE, Van Der Pol B, Dong Q, et al. Characteristic male urine microbiomes associate with asymptomatic sexually transmitted infection. PLoS One 2010;5:e14116.

16. Wolfe AJ, Toh E, Shibata N, et al. Evidence of uncultivated bacteria in the adult female bladder. J Clin Microbiol 2012;50:1376-83.

17. Lewis DA, Brown R, Williams J, et al. The human urinary microbiome; bacterial DNA in voided urine of asymptomatic adults. Front Cell Infect Microbiol 2013;3:41.

18. Hilt EE, McKinley K, Pearce MM, et al. Urine is not sterile: use of enhanced urine culture techniques to detect resident bacterial flora in the adult female bladder. J Clin Microbiol 2014;52:871-6.

19. Mostafa MH, Sheweita SA, O'Connor PJ. Relationship between schistosomiasis and bladder cancer. Clin Microbiol Rev 1999;12:97-111.

20. El-Bolkainy MN, Mokhtar NM, Ghoneim MA, et al. The impact of schistosomiasis on the pathology of bladder carcinoma. Cancer 1981;48:2643-8.

21. Gouda I, Mokhtar N, Bilal D, et al. Bilharziasis and bladder cancer: a time trend analysis of 9843 patients. J
Egypt Natl Canc Inst 2007;19:158-62.

22. Rosin MP, Saad el Din Zaki S, Ward AJ, et al. Involvement of inflammatory reactions and elevated cell proliferation in the development of bladder cancer in schistosomiasis patients. Mutat Res 1994;305:283-92.

23. Salem S, Mitchell RE, El-Alim El-Dorey A, et al. Successful control of schistosomiasis and the changing epidemiology of bladder cancer in Egypt. BJU Int 2011;107:206-11.

24. Marletta MA. Mammalian synthesis of nitrite, nitrate, nitric oxide, and N-nitrosating agents. Chem Res Toxicol 1988;1:249-57.

25. Adebayo AS, Suryavanshi MV, Bhute S, et al. The microbiome in urogenital schistosomiasis and induced bladder pathologies. PLoS Negl Trop Dis 2017;11:e005826.

26. $\mathrm{Xu} W$, Yang L, Lee $\mathrm{P}$, et al. Mini-review: perspective of the microbiome in the pathogenesis of urothelial carcinoma. Am J Clin Exp Urol 2014;2:57-61.

27. Bucevic Popovic V, Situm M, Chow CT, et al. The urinary microbiome associated with bladder cancer. Sci Rep 2018;8:12157.

28. Wu P, Zhang G, Zhao J, et al. Profiling the Urinary Microbiota in Male Patients With Bladder Cancer in China. Front Cell Infect Microbiol 2018;8:167.

29. DeGeorge KC, Holt HR, Hodges SC. Bladder Cancer: Diagnosis and Treatment. Am Fam Physician 2017;96:507-14.

30. Kamat AM, Colombel M, Sundi D, et al. BCGunresponsive non-muscle-invasive bladder cancer: recommendations from the IBCG. Nat Rev Urol 2017;14:244-55.

31. Ahn JJ, Ghandour RA, McKiernan JM. New agents for bacillus Calmette-Guerin-refractory nonmuscle invasive bladder cancer. Curr Opin Urol 2014;24:540-5.

32. Bajic P, Wolfe AJ, Gupta GN. Old instillations and new implications for bladder cancer: the urinary microbiome and intravesical BCG. BJU Int 2019;124:7-8.

33. McMillan A, Macklaim JM, Burton JP, et al. Adhesion of Lactobacillus iners AB-1 to human fibronectin: a key mediator for persistence in the vagina? Reprod Sci 2013;20:791-6.

34. Bellmunt J, de Wit R, Vaughn DJ, et al. Pembrolizumab as Second-Line Therapy for Advanced Urothelial Carcinoma. N Engl J Med 2017;376:1015-26.

35. Rosenberg JE, Hoffman-Censits J, Powles T, et al. Atezolizumab in patients with locally advanced and metastatic urothelial carcinoma who have progressed 
following treatment with platinum-based chemotherapy: a single-arm, multicentre, phase 2 trial. Lancet 2016;387:1909-20.

36. Sharma P, Retz M, Siefker-Radtke A, et al. Nivolumab in metastatic urothelial carcinoma after platinum therapy (CheckMate 275): a multicentre, single-arm, phase 2 trial. Lancet Oncol 2017;18:312-22.

37. Powles T, O'Donnell PH, Massard C, et al. Efficacy and Safety of Durvalumab in Locally Advanced or Metastatic Urothelial Carcinoma: Updated Results From a Phase 1/2 Open-label Study. JAMA Oncol 2017;3:e172411.

38. Apolo AB, Infante JR, Balmanoukian A, et al. Avelumab, an Anti-Programmed Death-Ligand 1 Antibody, In Patients With Refractory Metastatic Urothelial Carcinoma: Results From a Multicenter, Phase Ib Study. J Clin Oncol 2017;35:2117-24.

39. Routy B, Le Chatelier E, Derosa L, et al. Gut microbiome influences efficacy of PD-1-based immunotherapy against epithelial tumors. Science 2018;359:91-7.

40. Hahn AW, Froerer C, VanAlstine S, et al. Targeting Bacteroides in Stool Microbiome and Response to Treatment With First-Line VEGF Tyrosine Kinase Inhibitors in Metastatic Renal-Cell Carcinoma. Clin Genitourin Cancer 2018;16:365-8.

41. Derosa L, Hellmann MD, Spaziano M, et al. Negative association of antibiotics on clinical activity of immune checkpoint inhibitors in patients with advanced renal cell and non-small-cell lung cancer. Ann Oncol 2018;29:1437-44.

42. Lalani AA, Xie W, Braun DA, et al. Effect of Antibiotic Use on Outcomes with Systemic Therapies in Metastatic Renal Cell Carcinoma. Eur Urol Oncol 2020;3:372-81.

43. Porter CM, Shrestha E, Peiffer LB, et al. The microbiome in prostate inflammation and prostate cancer. Prostate Cancer Prostatic Dis 2018;21:345-54.

44. Shrestha E, White JR, Yu SH, et al. Profiling the Urinary Microbiome in Men with Positive versus Negative Biopsies for Prostate Cancer. J Urol 2018;199:161-71.

45. Liss MA, White JR, Goros M, et al. Metabolic Biosynthesis Pathways Identified from Fecal Microbiome Associated with Prostate Cancer. Eur Urol 2018;74:575-82.

46. Golombos DM, Ayangbesan A, O'Malley P, et al. The Role of Gut Microbiome in the Pathogenesis of Prostate Cancer: A Prospective, Pilot Study. Urology 2018;111:122-8.

47. Sfanos KS, Markowski MC, Peiffer LB, et al. Compositional differences in gastrointestinal microbiota in prostate cancer patients treated with androgen axistargeted therapies. Prostate Cancer Prostatic Dis 2018;21:539-48.

48. Feng Y, Ramnarine VR, Bell R, et al. Metagenomic and metatranscriptomic analysis of human prostate microbiota from patients with prostate cancer. BMC Genomics 2019;20:146.

49. Alanee S, El-Zawahry A, Dynda D, et al. A prospective study to examine the association of the urinary and fecal microbiota with prostate cancer diagnosis after transrectal biopsy of the prostate using 16sRNA gene analysis. Prostate 2019;79:81-7.

50. Banerjee S, Alwine JC, Wei Z, et al. Microbiome signatures in prostate cancer. Carcinogenesis 2019;40:749-64.

51. Graff JN, Alumkal JJ, Drake CG, et al. Early evidence of anti-PD-1 activity in enzalutamide-resistant prostate cancer. Oncotarget 2016;7:52810-7.

52. Matson V, Fessler J, Bao R, et al. The commensal microbiome is associated with anti-PD-1 efficacy in metastatic melanoma patients. Science 2018;359:104-8.

53. Gopalakrishnan V, Spencer CN, Nezi L, et al. Gut microbiome modulates response to anti-PD-1 immunotherapy in melanoma patients. Science 2018;359:97-103.

54. Reis Ferreira M, Andreyev HJN, Mohammed K, et al. Microbiota- and Radiotherapy-Induced Gastrointestinal Side-Effects (MARS) Study: A Large Pilot Study of the Microbiome in Acute and Late-Radiation Enteropathy. Clin Cancer Res 2019;25:6487-500.

55. Parker AS, Cerhan JR, Lynch CF, et al. History of urinary tract infection and risk of renal cell carcinoma. Am J Epidemiol 2004;159:42-8.

56. Jonasch E. NCCN Guidelines Updates: Management of Metastatic Kidney Cancer. J Natl Compr Canc Netw 2019;17:587-9.

57. Shepard DR, Garcia JA. Toxicity associated with the longterm use of targeted therapies in patients with advanced renal cell carcinoma. Expert Rev Anticancer Ther 2009;9:795-805.

58. Sternberg CN, Davis ID, Mardiak J, et al. Pazopanib in locally advanced or metastatic renal cell carcinoma: results of a randomized phase III trial. J Clin Oncol 2010;28:1061-8.

59. Motzer RJ, Hutson TE, Tomczak P, et al. Sunitinib versus interferon alfa in metastatic renal-cell carcinoma. N Engl J Med 2007;356:115-24.

60. Escudier B, Eisen T, Stadler WM, et al. Sorafenib in 
Page 10 of 10

advanced clear-cell renal-cell carcinoma. N Engl J Med 2007;356:125-34.

61. Pal SK, Li SM, Wu X, et al. Stool Bacteriomic Profiling in Patients with Metastatic Renal Cell Carcinoma Receiving Vascular Endothelial Growth Factor-Tyrosine Kinase Inhibitors. Clin Cancer Res 2015;21:5286-93.

62. Fijlstra M, Ferdous M, Koning AM, et al. Substantial decreases in the number and diversity of microbiota during chemotherapy-induced gastrointestinal mucositis in a rat model. Support Care Cancer 2015;23:1513-22.

63. Stringer AM, Gibson RJ, Logan RM, et al. Faecal microflora and beta-glucuronidase expression are altered in an irinotecan-induced diarrhea model in rats. Cancer Biol Ther 2008;7:1919-25.

64. Balar AV, Castellano D, O'Donnell PH, et al. First-line pembrolizumab in cisplatin-ineligible patients with locally advanced and unresectable or metastatic urothelial cancer (KEYNOTE-052): a multicentre, single-arm, phase 2 study. Lancet Oncol 2017;18:1483-92.

65. Sharma P, Callahan MK, Bono P, et al. Nivolumab monotherapy in recurrent metastatic urothelial carcinoma (CheckMate 032): a multicentre, open-label, two-stage, multi-arm, phase 1/2 trial. Lancet Oncol 2016;17:1590-8. 66. Massard C, Gordon MS, Sharma S, et al. Safety

Cite this article as: Nicolaro M, Portal DE, Shinder B, Patel HV, Singer EA. The human microbiome and genitourinary malignancies. Ann Transl Med 2020;8(19):1245. doi: 10.21037/atm-20-2976

\section{Nicolaro et al. Microbiome and genitourinary malignancies}

and Efficacy of Durvalumab (MEDI4736), an AntiProgrammed Cell Death Ligand-1 Immune Checkpoint Inhibitor, in Patients With Advanced Urothelial Bladder Cancer. J Clin Oncol 2016;34:3119-25.

67. Motzer RJ, Escudier B, McDermott DF, et al. Nivolumab versus Everolimus in Advanced Renal-Cell Carcinoma. N Engl J Med 2015;373:1803-13.

68. Rini BI, Plimack ER, Stus V, et al. Pembrolizumab plus Axitinib versus Sunitinib for Advanced Renal-Cell Carcinoma. N Engl J Med 2019;380:1116-27.

69. Vetizou M, Pitt JM, Daillere R, et al. Anticancer immunotherapy by CTLA-4 blockade relies on the gut microbiota. Science 2015;350:1079-84.

70. Flippot R, Dalban C, Laguerre B, et al. Safety and Efficacy of Nivolumab in Brain Metastases From Renal Cell Carcinoma: Results of the GETUG-AFU 26 NIVOREN Multicenter Phase II Study. J Clin Oncol 2019;37:2008-16.

71. McDermott DF, Sosman JA, Sznol M, et al. Atezolizumab, an Anti-Programmed Death-Ligand 1 Antibody, in Metastatic Renal Cell Carcinoma: Long-Term Safety, Clinical Activity, and Immune Correlates From a Phase Ia Study. J Clin Oncol 2016;34:833-42. 